\title{
Numerical Investigation of 2-D Wave Making Characteristics of a Submerged Hydrofoil
}

\author{
Murat AYYILDIZ1 ${ }^{1}$ Ahmet Ziya SAYDAM ${ }^{1,2}$, Murat ÖZBULUT ${ }^{1}$ \\ ${ }^{1}$ Faculty of Engineering, Piri Reis University, Turkey \\ ${ }^{2}$ Hidro-Teknik Nautical Design Technologies Ltd.,Turkey \\ muratayyildiz92@icloud.com; ORCID ID: https://orcid.org/0000-0001-9695-2564 \\ zsaydam@pirireis.edu.tr; ORCID ID: https://orcid.org/0000-0002-1266-9401 \\ mozbulut@pirireis.edu.tr; ORCID ID: https://orcid.org/0000-0001-6213-8783
}

\begin{abstract}
In this study, 2-D wave making characteristics of a submerged hydrofoil has been investigated in a numerical fashion. Experimental data available for different depths of submergence and flow velocities have been compared to the results obtained by a commercial RANS CFD code and an in-house SPH code. The capabilities of the numerical approaches in terms of capturing the free surface deformation have been assessed. At high Froude numbers, the induced wave profiles have been observed to exhibit an unsteady nature by both numerical methods. The pressure contours obtained from the numerical analysis have also been compared with each other. It has been seen that the agreement between the results of the well-established RANS method and recently progressing SPH technique is encouraging for further development.
\end{abstract}

Keywords: Open Channel Flow, CFD, SPH, RANS, Hydrofoil, Free Surface Hydrodynamics.

\section{Serbest Yüzeye Yakın Bir Kanada Ait Dalga Karakteristiğinin Sayısal Teknikler ile İncelenmesi}

Öz

Bu çalışmada, serbest su yüzeyine yakın bir hidrofoil etrafindaki akış, yani 2 boyutlu dalga yapımı problemi sayısal olarak incelenmiştir. Deney sonuçları farklı derinlikler ve akış hızlarında RANS hesaplamalı akışkanlar dinamiği kodu ve interpolasyonlu parçacık hidrodinamiği(iPH) yöntemi ile karşılaştırılmıștır. Sayısal yaklaşımların serbest su yüzeyi deformasyonunun tahmini açısından kabiliyetleri değerlendirilmiştir. Özellikle yüksek Froude sayılarında, indüklenen dalga profillerinin, her iki sayısal yöntemde de yüksek mertebede zamana bağlı (kararsız) bir doğası olduğu gözlemlenmiştir. Sayısal analizden elde edilen basınç hatları da birbiriyle karşılaştırılmıștır. Sayısal çözüm teknikleri açısından gelişimini büyük ölçüde tamamlamış RANS yönteminin sonuçları ile görece yeni sayılabilecek ve halen gelişimini devam ettirmekte olan IPH yönteminin sonuçları arasındaki uyumluluğun gelecek araştırma çalışmaları açısından ümit verici olduğu görülmüştür.

Anahtar Kelimeler: Açık Kanal Akışı, HAD, IPH, RANS, Hidrofoil, Serbest Su Yüzeyi. 


\section{Introduction}

Recently, particle-based numerical methods are gaining popularity in the field of numerical hydrodynamics. The meshless nature of the method is a promising feature for the method. In this study, the flow around a submerged hydrofoil will be investigated by the well-established RANS CFD utilizing a commercial package and Smoothed Particle Hydrodynamics (SPH) by an in-house code. Results will be compared with experimental data.

Hydrodynamics of submerged bodies is of interest mainly in the fields of naval architecture and fluid dynamics. Up to now, the wave profile induced by a submerged body has been investigated by various researchers. There are numerous experimental studies that may be utilized as validation cases for numerical techniques. Up to now, researchers have primarily used potential methods and RANS CFD for investigation of the performance of submerged bodies.

Salvesen's [1] work in 1966 clearly proved the importance of the effect of nonlinearity at the free surface, and it shows how results may be improved by the second order theory than by the linear theory.

Duncan [2] in 1983 experimented with NACA 0012 hydrofoil and measured the wave profile for different submergence values, incidence angles, and flow velocities.

Çalışal et al [3] studied the numerical results of the potential theory and compared them with the experimental results given by Salvesen. The iterative solution was observed to give better results than the first order solution of Salvesen but not as good as the second order solution if the experimental values are used as a standard for comparison.

N. Xie and D. Vassolos [4] developed a panel method for predicting the steady flow around a submerged hydrofoil with a finite aspect ratio under potential flow assumptions. The technique utilizes constant-strength doublets and source density distribution around the hydrofoil. After obtaining the solution of the doublets on the sources at the interface, the numerical results of pressure, lift and resistance coefficients and also wave profiles are calculated for different Froude numbers and depths of submergence to demonstrate the influence of free surface and aspect ratio performance of the hydrofoil.

Y. Uslu and S. Bal [5] have studied the hydrodynamic forces, wave elevation characteristics and distribution of pressure around 2D and 3D bodies by boundary element method. The boundary element method is of iterative nature, which was originally configured for both 2-D and 3-D cavitating foil shapes and ship-like bodies travelling with a fixed velocity beneath or on the free surface has been applied to a 2-D hydrofoil with an angle of incidence.

Gretton et al have conducted [6] RANS CFD simulations of a submerged foil. NACA 0012 hydrofoil at a Froude number of 0.567 has been used for the simulations. CFD simulations examined the wave elevation and the hydrodynamic forces and moments.

Rhee and Stern [7] studied Duncan's experiment with numerical techniques. Analyses were comprised of the influence of dimensional decoupling and solution domain dimensions and it has been concluded that breaking waves were induced, possessing an unsteady wave profile.

H. Ottans et al [8] used RANS CFD to simulate a cylinder located beneath the free surface under the influence of regular waves with varying wave heights, wave periods and different submergence depths.

As for the particle based solutions, B. Boucasse et al [9] recently proposed SPH based numerical scheme results which tackle flow around cylinder beneath the free surface with a numerous number test cases depending on the submergence to depth ratios and Froude numbers. 
The main objective of the present work is to investigate 2-D wave making problem in terms of two numerical approaches: (i) mesh-based Reynolds Averaged NavierStokes (RANS) and (ii) particle-based Smoothed Particle Hydrodynamics (SPH) methods. Free surface deformations behind the profile are compared with the experimental findings of the literature [1] for two submergence levels of the profile and three different Froude numbers for each level.

\section{Methodology}

In the present study, the induced wave profile of a hydrofoil under free surface has been analyzed by RANS CFD and SPH methods. The variation of wave profiles with increasing depth is also investigated. The utilized geometry and the experimental results have been obtained from Salvesen's work [1]. The foil profile is given in Figure 1 and the channel geometry details are given in Figure 2.

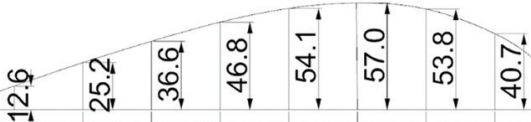
36.936 .9 36.9 36.9 36.9 36.9 36.9 36.9 .36 .7 332.0

Figure 1. Foil Thicknesses Along the Chord ( $\mathrm{mm}$ )
Table 1. Test Matrix

\begin{tabular}{|c|c|c|c|}
\hline $\mathrm{h} / \mathrm{D}$ & \multicolumn{3}{|c|}{$\mathrm{Fr}$} \\
\hline 0.48 & 0.55 & 0.71 & 0.87 \\
\hline 0.57 & 0.50 & 0.65 & 0.79 \\
\hline
\end{tabular}

\subsection{RANS Modelling}

The experimental geometry has been converted to a solution domain for RANS CFD analysis by Rhinoceros and imported to Ansys Design Modeler for Boolean operations. The mesh generation has been conducted by Ansys Mesher.

During the meshing process, utmost attention has been paid to properly mesh the surface of the hydrofoil and capture the boundary layer and the free surface elevation. A typical mesh in way of the hydrofoil and the free surface is given in Figure 3.

During the RANS simulations, ANSYS CFX software has been used. VOF model has been utilized for capturing the freesurface. SST k- $\omega$ turbulence model has been used along with second order solver and turbulence numerics.

Before the actual analysis, a grid independence study has been planned according to ITTC's methodology [10]. The hydrofoil has been analyzed at 0.381 $\mathrm{m}$ depth for $1.676 \mathrm{~m} / \mathrm{s}$ velocity. 5 different

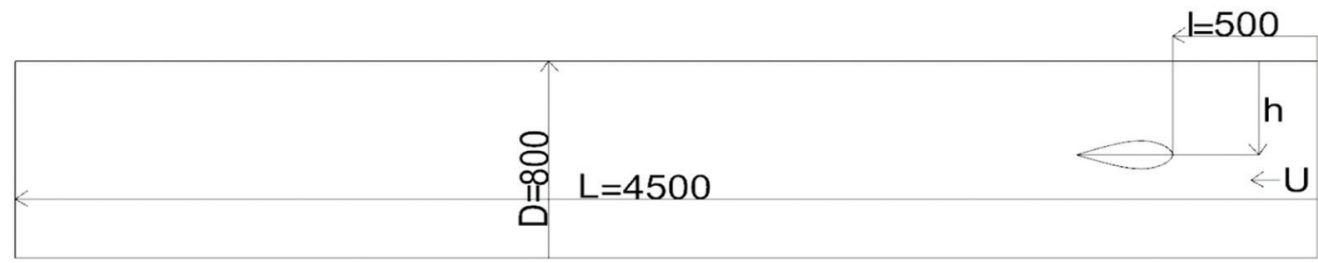

Figure 2. Channel Dimensions ( $\mathrm{mm}$ )

The numerical test matrix is given in Table 1.

Inflow velocities have been nondimensionalized by Froude number based on submergence $(\mathrm{h})$ :

$$
F r=\frac{U}{\sqrt{g h}}
$$

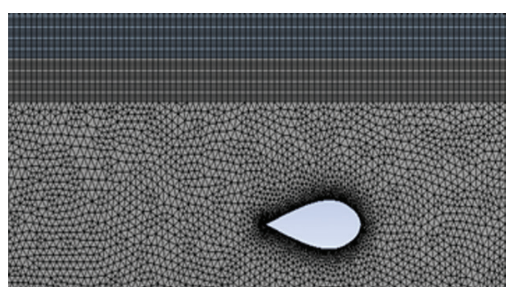

Figure 3. Grid Density in Way of Hydrofoil and Free Surface 
grids have been prepared with varying mesh sizes in way of the expected free surface region. A grid independent solution in terms of maximum wave amplitude has been achieved with the third solution, with a total of 1,258,499 elements. The variation of maximum wave amplitude with number of cells is given in Figure 4.

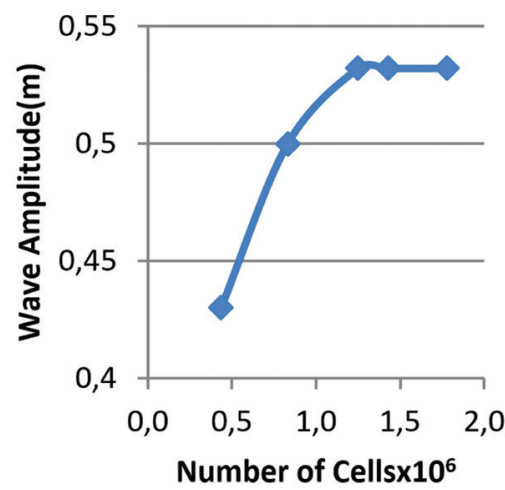

Figure 4. Variation of Wave Amplitude with Mesh Density

The boundary conditions are given in Figure 5. Due to the symmetric nature of the flow, a half model has been utilized.

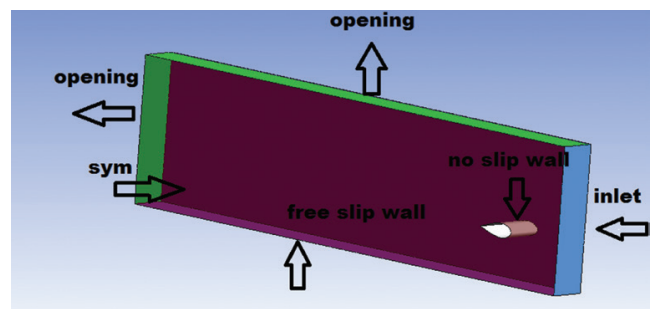

Figure 5. Boundary Conditions Used in The Solution Domain for RANS Solutions

\subsection{SPH Modelling}

Smoothed Particle Hydrodynamics (SPH) is a fully Lagrangian and meshless method which has many intrinsic advantages on the modeling of highly non-linear violent free surface problems [11]. These prominent capabilities on the modeling of high-deformation free surface flows attract the interest of the researchers, especially in the field of ship hydrodynamics, which results in continuous investigation and exploration studies on the development of the method in the recent years $[12,13,14]$.

This work also aims to put a prudent contribution to the improvement and expansion of SPH method by implementing previously developed numerical scheme [15] with an additional kernel gradient correction treatment. To keep the compactness of the text and prevent any redundancy on the coherence of the paper, readers are kindly referred to [16] for the SPH discretization of governing equations. Only new kernel gradient correction algorithm which is firstly included into the numerical scheme during the simulations of this work is given as follows:

$$
\begin{aligned}
& \nabla^{C} W_{i j}=L\left(\boldsymbol{r}_{i}\right) \nabla_{i} W_{i j} \\
& L\left(\boldsymbol{r}_{i}\right)=\left[\sum_{j=1}^{N}\left(\begin{array}{cc}
x_{j i} \frac{\partial W_{i j}}{\partial x_{i}} & y_{j i} \frac{\partial W_{i j}}{\partial x_{i}} \\
x_{j i} \frac{\partial W_{i j}}{\partial y_{i}} & y_{j i} \frac{\partial W_{i j}}{\partial y_{i}}
\end{array}\right]^{-1} V_{j}\right.
\end{aligned}
$$

Here, superscript $C$ denotes the corrected kernel gradient, $W_{i j}$ is the quintic kernel function, $\mathbf{r}_{\mathbf{i}}$ is the position vector, $V_{j}$ equal to the volume of each particle, $x_{j i}$ and $y_{j i}$ refer to the horizontal and vertical distances between particles ' $j$ ' and ' $i$ ', respectively.

The boundary conditions in SPH simulations are set as follows: To avoid the possible grounding effects, the bottom wall boundary condition is applied as free-slip by generating ghost particles [15]. Open channel inlet and outlet boundaries are modeled as a periodic boundary. The boundary condition on the solid profile is modeled as no-slip. No special treatment is implemented for the free surface particles while SPH technique naturally satisfies the dynamic free surface condition $\left(p=p_{a t m}\right)$. During SPH simulations 57897 fluid particles and 784 solid particles are assigned to discretize the problem domain. 


\section{Results and Discussion}

Analysis by RANS and SPH methods have been completed as per the test matrix given in Table 1. As stated previously, the main purpose of the work is to investigate the capabilities of the numerical techniques in terms of capturing the waves generated by the submerged hydrofoil. With this respect, the wave profiles obtained by RANS CFD and SPH techniques have been compared with Salvesen's experimental results and first and second order solutions from the same study [1]. Results are given for $h / D=0.48$ in Figures $6 \mathrm{a}, \mathrm{b}$ and $\mathrm{c}$ and for $h / D=0.57$ in Figures $7 \mathrm{a}, \mathrm{b}$ and c respectively.

It is important to report that the simulations are carried out at a constant depth of the channel (D) for two submergence levels of profile and it is examined that utilization of higher depth values does not alter the free surface profiles. In order to keep the mesh elements in an admissible range together with avoiding grounding effects arises from the bottom wall boundary, an optimum value of $\mathrm{D}=800 \mathrm{~mm}$ is observed to provide sufficient accuracy in the results for each submergence levels of the profile.

It is seen that the wave profiles generated by the submerged hydrofoil, obtained from the experimental study and the numerical results tend to agree well as the inflow velocity increases. At low speeds, while the initial agreement between the wave amplitudes is in a match, they tend to deteriorate along the channel. The same conclusion is also applicable to the 1st and 2nd order theory results. For the lowest speed cases, as the magnitude of the wave amplitude is at the order of two centimeters, experimental uncertainties are expected to reach relatively substantial levels when compared to the higher speed cases. With increasing depth, many compatible results are obtained with both of the numerical tools.

At higher speeds, there is an excellent agreement between RANS and experimental results and the agreement between experiments and SPH results are substantially improved. While minor deviations may exist in the amplitudes, the length of the induced waves agree well among all the methods.

It is also worth noting that, at high speeds, transient effects have been captured with both numerical tools. The induced wave at high-speed cases has been seen to be of unsteady nature; this being confirmed by the disagreement between the experiments and steady state RANS solution. With the utilization of the unsteady solver, it has been possible to capture the experimental wave profile after a certain solution time, and a repetitive wave profile variation has been observed.

Apart from the wave profiles, the pressure field inside the solution domain, obtained from both numerical methods have been compared. The pressure values have been non-dimensionalized into pressure coefficients by using instantaneous velocities. Hydrostatic pressure has been excluded from the total pressure at all cases. For convenience, the pressure coefficients for the highest inflow velocity for both depths have been given in Figures $8 \mathrm{a}$ and $8 \mathrm{~b}$.

Considering the unsteady nature of the 2-d wave making problem, the pressure contours obtained from the numerical techniques are in reasonable agreement between each other. It is the authors' opinion that it is not possible to distinguish the uncertainty levels arising from the unsteadiness in the flow field and differences in the numerical approaches of the techniques. As different order of magnitudes have been adopted in the timestepping schemes -mainly owing to the robustness of the commercial CFD package enabling the use of higher time-steps- may result in obtaining different instantaneous pressure oscillations that tend to reflect 
the final wave profile. Additionally, the resolution in the discretization of the flow field varies substantially among the two techniques, which may be considered as a reason for the minor deviations in the pressure coefficients.

\section{Conclusions}

The flow around a submerged hydrofoil has been investigated by a commercial RANS CFD package and an in-house SPH code. Effect of submergence depth and Froude number on the induced wave profile has been investigated. Results have been compared with experimental data from the literature.

The agreement achieved between the wave profiles near the vicinity of the trailing edge at lower speeds tends to deteriorate with the progression of the flow towards the channel outlet.

The agreement of wave profiles at higher speeds between experimental data and numerical results are improved substantially. RANS CFD and experimental results show an excellent agreement and SPH results tend to slightly overpredict the wave amplitude.

As the uncertainties associated with the experiment and numerical works have not been thoroughly scrutinized within the current scope of the study, further work is planned in order to quantify the uncertainties and obtain more comprehensive conclusions. ITTC's methodology will be followed for quantifying the uncertainties associated with both RANS and SPH techniques.

\section{Acknowledgements}

The authors would like to thank Prof. Ömer Gören (ITU) and Prof. Mehmet Yıldız (Sabanci University) for their guidance on the exhibition of physical problem parameters and precious contributions on the assessment of the observed results.

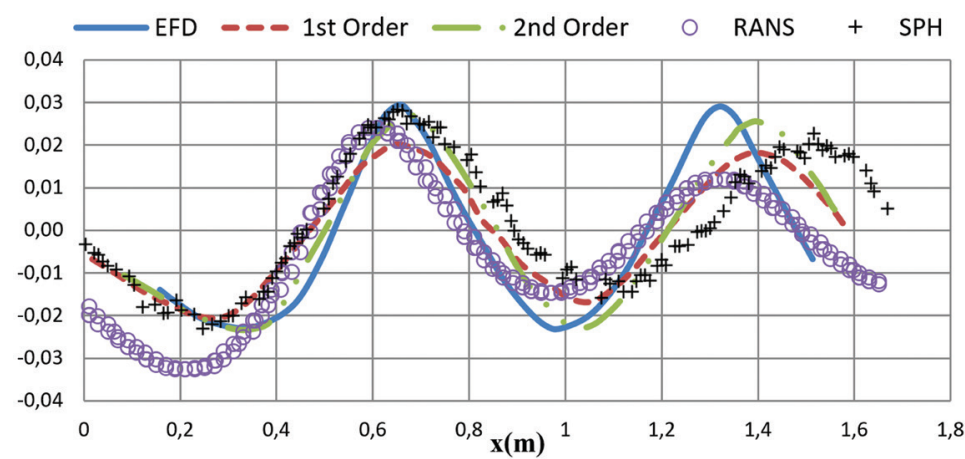

Figure 6. (a)

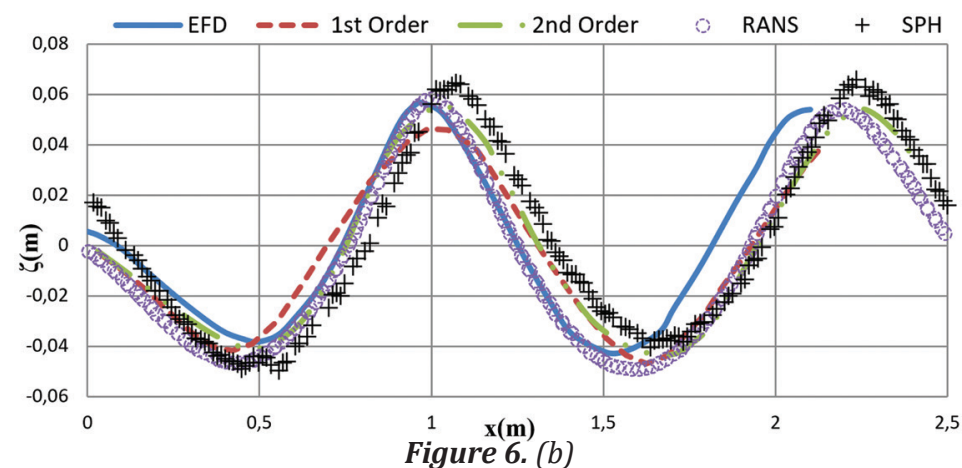

Figure 6. Wave Profiles for $h / D=0.48$ (a) $F r=0.55$ (b) $F r=0.71$ (c) $F r=0.87$ 


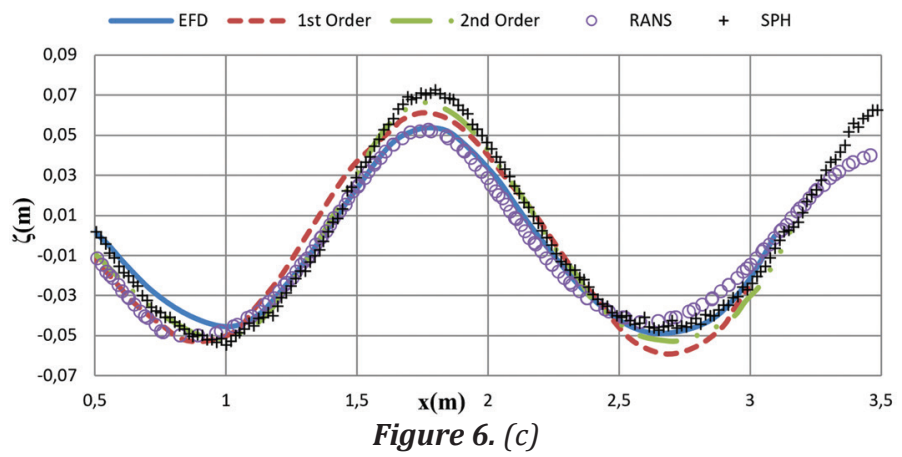

Figure 6. Wave Profiles for $h / D=0.48$ (a) $F r=0.55$ (b) $F r=0.71$ (c) $F r=0.87$ (cont')

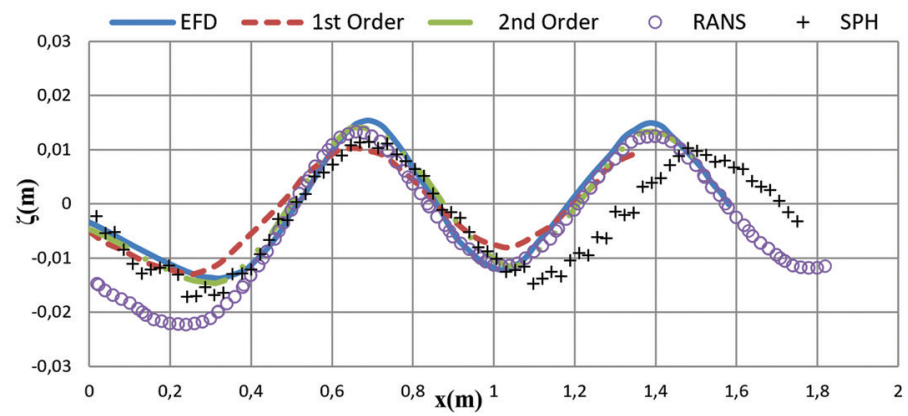

Figure 7. (a)

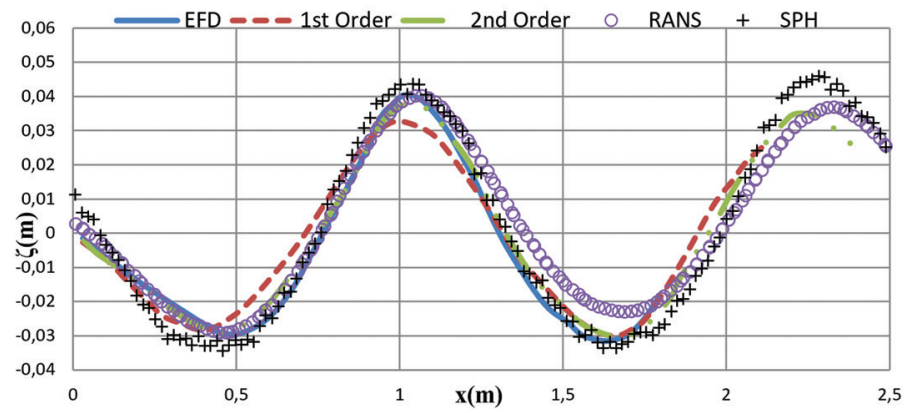

Figure 7. (b)

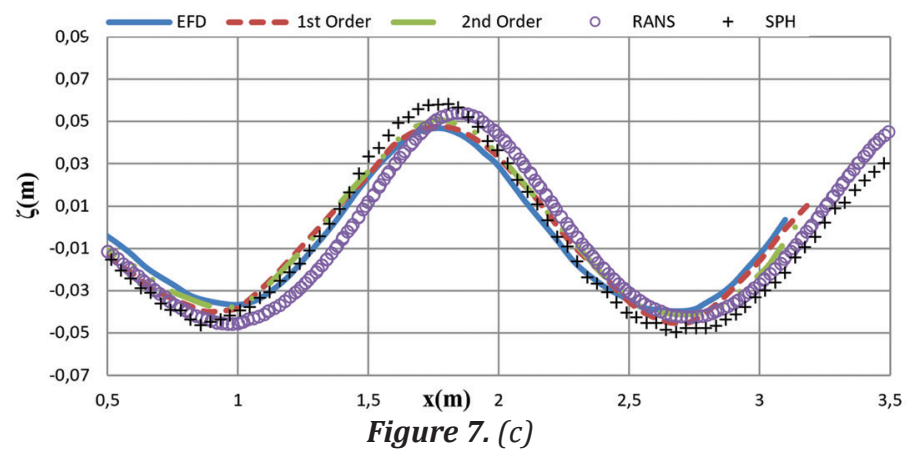

Figure 7. Wave Profiles for $h / D=0.57$ (a) $F r=0.50$ (b) $F r=0.65$ (c) $F r=0.79$ 


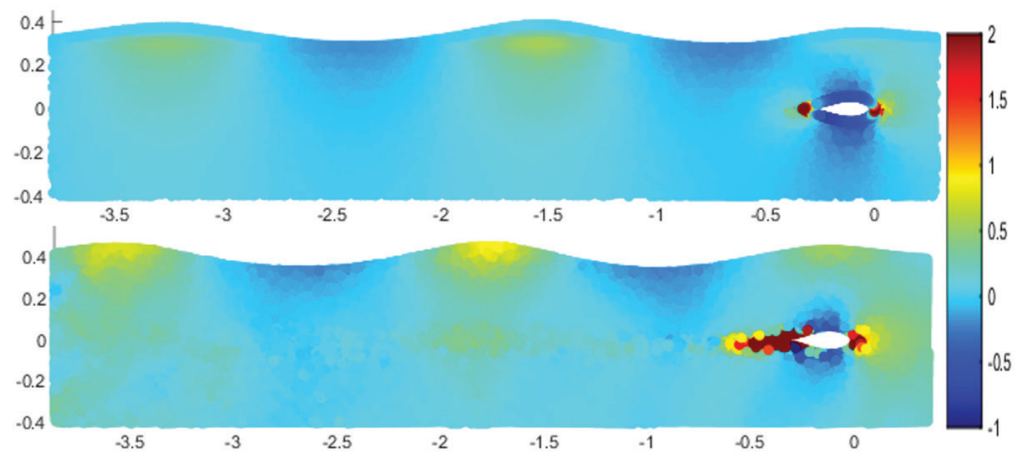

Figure 8. (a)

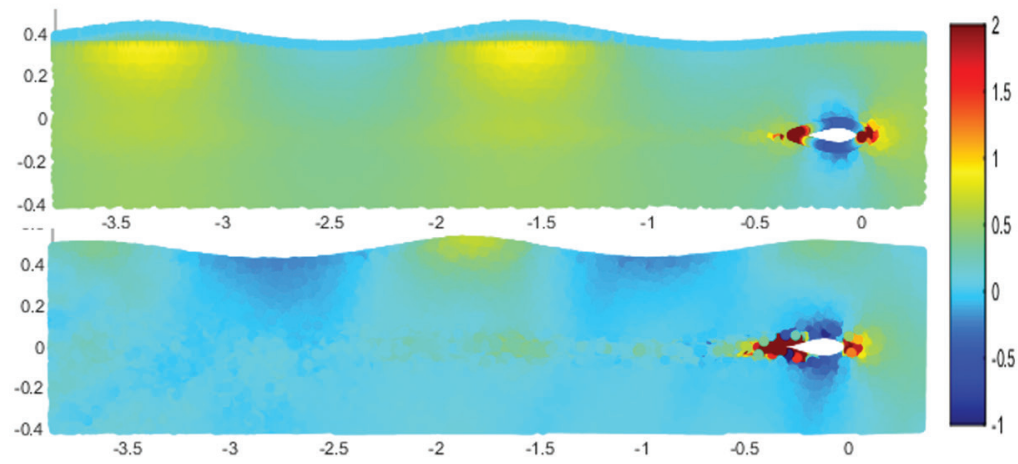

Figure 8. (b)

Figure 8. Contours of Pressure Coefficient for RANS (top) and SPH (bottom) Methods (a) $h / D=48$ and $F r=0.87(b) h / D=57$ and $F r=0.79$

\section{References}

[1] Salvesen, S. (1966). On Secondorder Wave Theory For Submerged Two Dimenional Body, Doctor of Philosophy in the University of Michigan.

[2] Duncan, J H. (1983). The Breaking and Non-breaking. Wave Resistance of a Two-Dimensional Hydrofoil, Journal of Fluid Mechanics, Vol. 126, pp. 507-520.

[3] Çalışal, S.M. Gören, Ö. and Okan, B. (1991). On an Iterative Solution for Nonlinear Wave Calculatons, Journal of Ship Research, Vol. 35,No 1, pp. 9914.

[4] Xie, N. Vassalos, D. (2007). Performance Analysis of 3D Hydrofoil Under Free Surface, Ocean Engineering 34(8-9):1257-1264.
[5] Uslu, Y. and Bal, S. (2008) Numerical Prediction of Wave Drag of 2-D and 3-D Bodies under or on a Free Surface, Turkish Journal of Engineering and Environmental Science, 32:177-188.

[6] Gretton I., Bryden I.,Couch J., and Ingraml, M.(2010) The CFD Simulation of a Lifting Hydrofoil in Close Proximity to a Free Surface, International Conference on Ocean, Offshore and Artic Engineering, June 6-11,2010

[7] Rhee, S.H.,Stern, F., (2002) RANS Model for Spilling Breaking Waves, Journal of Fluids Engineering, 124: 424-432

[8] Ottens, H., Pistidda A., van Dijk R., (2014). CFD Analysis of Waves Over a Submerged Cylinder in Close Proximity of the Free Surface, International Conference on Ocean,Offshore and Artic Engineering June 8-13,2014. 
[9] Boucasse, B. Colagrossi, A. Marrone, S. and Souto-Iglesias, A. (2017). SPH modelling of viscous flow past a circular cylinder interacting with a free surface, Computers and Fluids, 146:190-212

[10] ITTC - Recommended Procedures and Guidelines (2008) Uncertainty Analysis in CFD Verification and Validation Methodology and Procedures

[11] Antuono, M. Colagrossi, A. Marrone, S. and Molteni, D. (2010). Freesurface flows solved by means of SPH schemes with numerical diffusive terms, Computer Physics Communications 181:532-549.

[12] Oger, G. Marrone, S. Le Touze, D. and De Leffe, M. (2016). SPH accuracy improvement through the combination of a quasi-Lagrangian shifting transport velocity and consistent ALE formalisms, Journal of Computational Physics, 313:7698.

[13] Shadloo, M.S. Weiss, R. Yildiz, M. and Dalrymple, R.A. (2015). Numerical Simulation of Long Wave Run-up for Breaking and Non-breaking Waves, International Journal for Offshore and Polar Engineering, 25(1):1-7.

[14] Ferrand, M. Laurance, R. Rogers, B.D. Violeau, D. and Kassiotis, C. (2013). Unified Semi-analytical Wall Boundary Conditions for Inviscid, Laminar or TurbulentFlows in the Meshless SPH Method, International Journal for Numerical Methods in Fluids, 71(4):446-472.

[15] Özbulut, M. Tofighi, N. Gören, Ö. and Ylldız, M. (2018). Investigation of Wave Characteristics in Oscillatory Motion of Partially Filled Rectangular Tanks, Journal of Fluids Engineering, 140(4):041204-11 pages.
[16] Özbulut, M. Yıldız, M. and Gören, Ö. (2014). A numerical investigation into the correction algorithms for SPH method in modeling violent free surface flows, International Journal of Mechanical Sciences, 79:56-65. 